\title{
Vespa velutina nigrithorax Lepeltier, 1836 from Hamburg (Northern Germany) shares the same COI haplotype with other European populations
}

\author{
Martin Husemann', Lara-Sophie Dey', Oliver Hawlitschek' \\ I Centrum für Naturkunde, Universität Hamburg, Martin-Luther-King-Platz 3, 20146, Hamburg, Germany \\ Corresponding author: Martin Husemann (martin.husemann@uni-hamburg.de)
}

Academic editor: Michael Ohl | Received 29 July 2020 | Accepted 24 August 2020 | Published 30 October 2020

http://zoobank.org/541C2AE4-5747-4EB3-85BC-8467204ACBE8

Citation: Husemann M, Dey L-S, Hawlitschek O (2020) Vespa velutina nigrithorax Lepeltier, 1836 from Hamburg (Northern Germany) shares the same COI haplotype with other European populations. Journal of Hymenoptera Research 79: 111-115. https://doi.org/10.3897/jhr.79.57048

\begin{abstract}
The yellow-legged, or Asian hornet, Vespa velutina, has invaded large parts of South-Western Europe and now starts spreading further north. Recently, it has been reported from Hamburg, Northern Germany. Yet, the origin of this new invasion is not clear as the founders may have come either from Southern Europe or from Asia. We here use COI sequences to test these alternatives and find that the specimens from Hamburg share the same haplotype with all Southern European samples. This suggests that the species has been transported long distance from other Europe to Northern Germany and shows further its high invasion potential.
\end{abstract}

\section{Keywords}

Asian hornet, France, honey bees, Italy, yellow legged hornet

\section{Introduction}

The Asian yellow legged hornet (Vespa velutina Lepeltier, 1836) was introduced to Southern Europe via pottery from China before 2004 (Haxaire et al. 2006) and has since then spread across large parts of Europe (Villemant et al. 2006; Rome and Villemant 2020). Previous genetic studies suggested that few or a single mated female gave rise to the invasion (Arca et al. 2015), suggesting an extreme founder effect reflected in the presence of 
a single mitochondrial haplotype in the invaded regions. Most recently, the species was found in Hamburg, Northern Germany. While only a single individual was described in the original first record (Husemann et al. 2020), subsequently several more specimens from a second location in Hamburg close to the original record and a nest were found. Later in 2020 more individuals at another location more distant of the original find were recovered. However, the origin of these specimens remained unclear. The founding specimens may either have been transported from Southern Europe or, possibly, a second time from the Asian native range of $V$. velutina. The latter may be a valid alternative as Hamburg is one of the major harbors in Germany and as such is a hub for many alien species (e.g. Kraepelin 1900; Weidner 1981; Nehring 2006). Therefore, we sequenced the COI gene of nine specimens recently collected in Hamburg and compared them to all publically available sequence data of the species to test the two alternative hypotheses of 1) an invasion from Southern Europe, or 2) a second invasion from Asia.

\section{Materials and methods}

We sequenced the COI gene for nine specimens from Hamburg from five locations and two specimens from Paris in our analyses: two specimens from $53.543056^{\circ} \mathrm{N}$, $10.073639^{\circ} \mathrm{E}$, collected in fall 2019 in a wasp trap; two specimens from $53.570915^{\circ} \mathrm{N}$, $9.850126^{\circ} \mathrm{E}(17.08 .2020)$; three specimens from $53.569317^{\circ} \mathrm{N}, 9.850461^{\circ} \mathrm{E}$ (18.08.2020); one specimen from $53.575623^{\circ} \mathrm{N}, 9.856934^{\circ} \mathrm{E}(14.08 .2020)$; one specimen from $53.539700^{\circ} \mathrm{N}, 10.058650^{\circ} \mathrm{E}(27.07 .2020)$; and two specimens from Paris, Jardin des Plantes ( $48.844708^{\circ} \mathrm{N}, 2.362767^{\circ} \mathrm{E} ; 23.07 .2020$, leg. Q. Rome). We extracted DNA from one leg of each specimen using a Chelex protocol (Walsh et al. 1991) and amplified the DNA barcoding fragment of the cytochrome C oxidase subunit I (COI) using the primers HCO / LCO (Folmer et al. 1994) using a standard DNA barcoding protocol. Sequencing was performed by Macrogen, Inc. (Amsterdam, NL).

We further downloaded all available sequences for Vespa velutina from BOLD systems (90 sequences, plus 11 newly generated sequences) with sequences of Vespa crabro from Canada and of Vespa mandarinia from Nepal as outgroups. All sequences were aligned using MUSCLE (Edgar 2004) as implemented in Geneious v. 6.1.8. (Kearse et al. 2012). The alignment was trimmed to $544 \mathrm{bp}$. For the haplotype network analysis, the two outgroup sequences and two BOLD sequences of $V$. velutina which showed to be strongly divergent were removed ( $\mathrm{N}=97$ sequences remained).

We estimated the most suitable substitution model using MrModeltest v.2.3 (Nylander 2004). The most suitable model was determined as GTR+G based on the AIC. In order to adjust for rate heterogeneity we used the reversible jump model in MrBayes v. 3.2.6 (Ronquist et al. 2012). We ran the simulation for 10 million generations sampling every 1,000 generations for a total of 10,000 final samples. Convergence was confirmed with average split frequencies being below 0.01. Trees were visualized with FigTree v. 1.4.2 (Rambaut 2008). We further constructed a TCS network using PopArt (Leigh and Bryant 2015) using the default parameters and different color coding for each country. 


\section{Results and discussion}

Nine specimens from Hamburg and two from Paris were successfully sequenced (NBCI Accession numbers MT941771-MT941781), and we confirmed the species identity as Vespa velutina (in line with the morphological identification) using the BLAST algorithms of the NCBI and BOLD databases. All 11 new sequences were identical. The best hits were for $V$. velutina without subspecies designation in both databases. The best hits with subspecies designation were for $V$. v. nigrithorax. The Bayesian phylogenetic tree was poorly resolved due to the low divergence of sequences (data not shown). The haplotype network clearly separates haplotypes from Indonesia and Malaysia (Fig. 1); these represent the subspecies V.v. velutina Lepeletier, 1836, $V . v$. ardens Buysson, 1905, and V. v. celebensis Perkins, 1910 from Indonesia and $V$. $v$. divergens Perkins, 1910 from Malaysia. The specimen from Taiwan represents the subspecies V. v. flavitarsus Sonan, 1939, which is less clearly separated from the majority of haplotypes representing the European invasive V.v. nigrithorax Buysson, 1905. The Indian samples, formerly described as V. v. auraria Smith, 1852 and $V . v$. variana Vecht, 1957 from Thailand and Vietnam are not clearly separated from haplotypes of V. v. nigrithorax. Vespa v. nigrithorax shows some diversity with several haplotypes in Asian samples, yet, all European invasive locations share a single haplotype in accordance with the hypothesis of Arca et al. (2015) and Granato et al. (2019) that a single

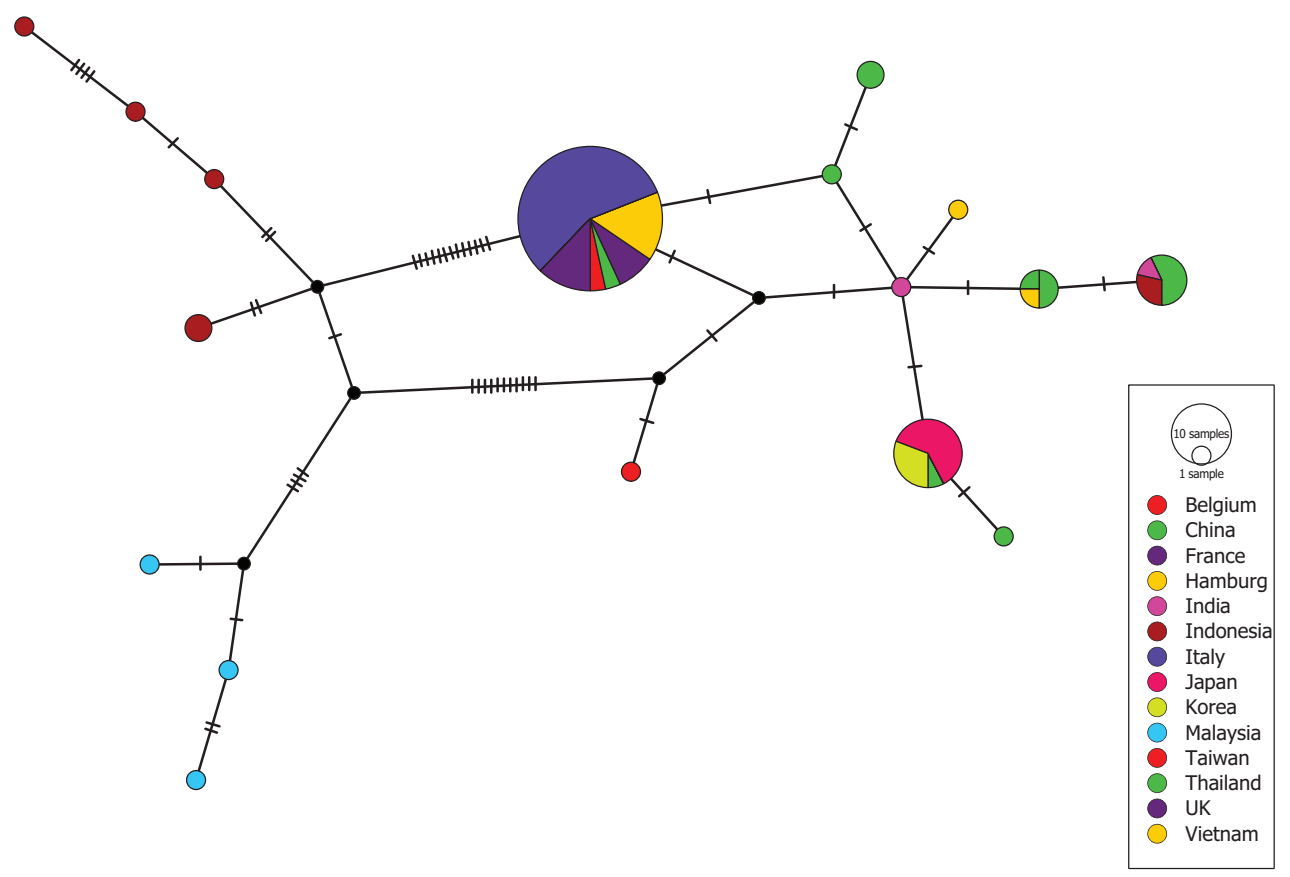

Figure I. Haplotype network showing the relationships of the specimens from Hamburg compared to specimen entries from the BOLD database (Network created in PopArt). 
or few females founded all invasive populations in Europe. Also, the specimens from Hamburg share this haplotype clearly pointing to a southern European origin of these specimens and hence making a second invasion from Asia unlikely.

The presence of $V . v$. nigrithorax in Hamburg remains surprising given the large distance to any other European populations. Considering the interest in the species and the reporting duties by the EU, it remains unlikely that the species has reached Northern Germany on natural routes without being seen. The large gap in occurrence in central Germany hence suggests that the species likely was anthropogenically transported over a long distance from Southern Europe to Northern Germany. This once more demonstrates the high invasion potential of the species.

\section{Acknowledgements}

We thank Dr. Willi Müller, Oliver Wieckhorst and several anonymous citizen scientists for reporting and recovering the additional specimens. Thank goes to Quentin Rome for specimens from France. We also thank Melanie Larisch and Sajad Noori for support in the molecular lab. Finally, we want to thank Quentin Rome and Christian Hach for critical comments on a previous version of the manuscript.

\section{References}

Arca M, Mougel F, Guillemaud T, Dupas S, Rome Q, Perrard A, Muller F, Fossoud A, Capdevielle-Dulac C, Torres-Leguizamon M, Chen XX, Tan JL, Jung C, Villemant C, Arnold G, Silvain J-F (2015) Reconstructing the invasion and the demographic history of the yellow-legged hornet, Vespa velutina, in Europe. Biological Invasions 17: 2357-2371. https://doi.org/10.1007/s10530-015-0880-9

Edgar RC (2004) MUSCLE: multiple sequence alignment with high accuracy and high throughput. Nucleic Acids Research 32: 1792-1797. https://doi.org/10.1093/nar/gkh340

Folmer O, Black M, Hoeh W, Lutz R, Vrijenhoek R (1994) DNA primers for amplification of mitochondrial cytochrome $\mathrm{c}$ oxidase subunit I from diverse metazoan invertebrates. Molecular Marine Biology and Biotechnology 3: 294-299.

Granato A, Negrisolo E, Bonomi J, Zulian L, Cappa F, Bortolotti L, Mutinelli F (2019) Recent confirmation of a single haplotype in the Italian population of Vespa velutina. Biological Invasions 21: 2811-2817. https://doi.org/10.1007/s10530-019-02051-4

Haxaire J, Tamisier J-P, Bouguet J-P (2006) Vespa velutina, 1836, une redoutable nouveauté pour la faune der France (Hym., Vespidae). Bulletin de la Société entomologique de France 111: 1-194.

Husemann M, Sterr A, Maack S, Abraham R (2020) The northernmost record of the Asian hornet Vespa velutina nigrithorax (Hymenoptera, Vespidae). Evolutionary Systematics 4: 1-4. https://doi.org/10.3897/evolsyst.4.47358 
Kearse M, Moir R, Wilson A, Stones-Havas S, Cheung M, Sturrock S, Buxton S, Cooper A, Markowitz S, Duran C (2012) Geneious basic: an integrated and extendable desktop software platform for the organization and analysis of sequence data. Bioinformatics 28: 1647-1649. https://doi.org/10.1093/bioinformatics/bts199

Kraepelin K (1901) Ueber die durch den Schiffsverkehr in Hamburg eingeschleppten Tiere. 2. Beiheft zum Jahrbuch der Hamburgischen Wissenschaftlichen Anstalten 18: 183-209.

Leigh, JW, Bryant D (2015) PopART: Full-feature software for haplotype network construction. Methods in Ecology and Evolution 6: 1110-1116. https://doi.org/10.1111/2041-210X.12410

Nehring S (2006) Four arguments why so many alien species settle into estuaries, with special reference to the German river Elbe. Helgoland Marine Research 60: 127-134. https://doi.org/10.1007/s10152-006-0031-x

Nylander JAA (2004) MrModeltest v2. Program distributed by the author. Evolutionary Biology Centre, Uppsala University.

Rambaut A (2008) FigTree v.1.1.2 2008. http://tree.bio.ed.ac.uk/software/figtree/

Rome Q, Villemant C (2020) Le Frelon asiatique Vespa velutina. Inventaire National du Patrimoine Naturel - Muséum national d'Histoire naturelle [Ed]. http://frelonasiatique.mnhn. fr/home/ [accessed on 27/03/2020]

Ronquist F, Teslenko M, van der Mark P, Ayres DL, Darling A, Höhna S, Huelsenbeck JP (2012) MrBayes 3.2: Efficient Bayesian phylogenetic inference and model choice across a large model space. Systematic Biology 61: 539-542. https://doi.org/10.1093/sysbio/sys029

Villemant C, Haxaire J, Streito J (2006) The discovery of the Asian hornet Vespa velutina in France. Insectes 143: 1-5.

Walsh PS, Metzger DA, Higuchi R (1991) Chelex 100 as a medium for simple extraction of DNA for PCR-based typing from forensic material. Biotechniques 10: 506-513.

Weidner H (1981) Einschleppung von Heuschrecken (Saltatoria und Phasmida) nach Hamburg. Anzeiger für Schädlingskunde, Pflanzenschutz und Umweltschutz 54: 65-67. https://doi.org/10.1007/BF01902230 